Teachers

Tin usurensiry or

\title{
and Curriculum
}

KAIAKO ME TE MARAUTANGA

VOLUME 112009

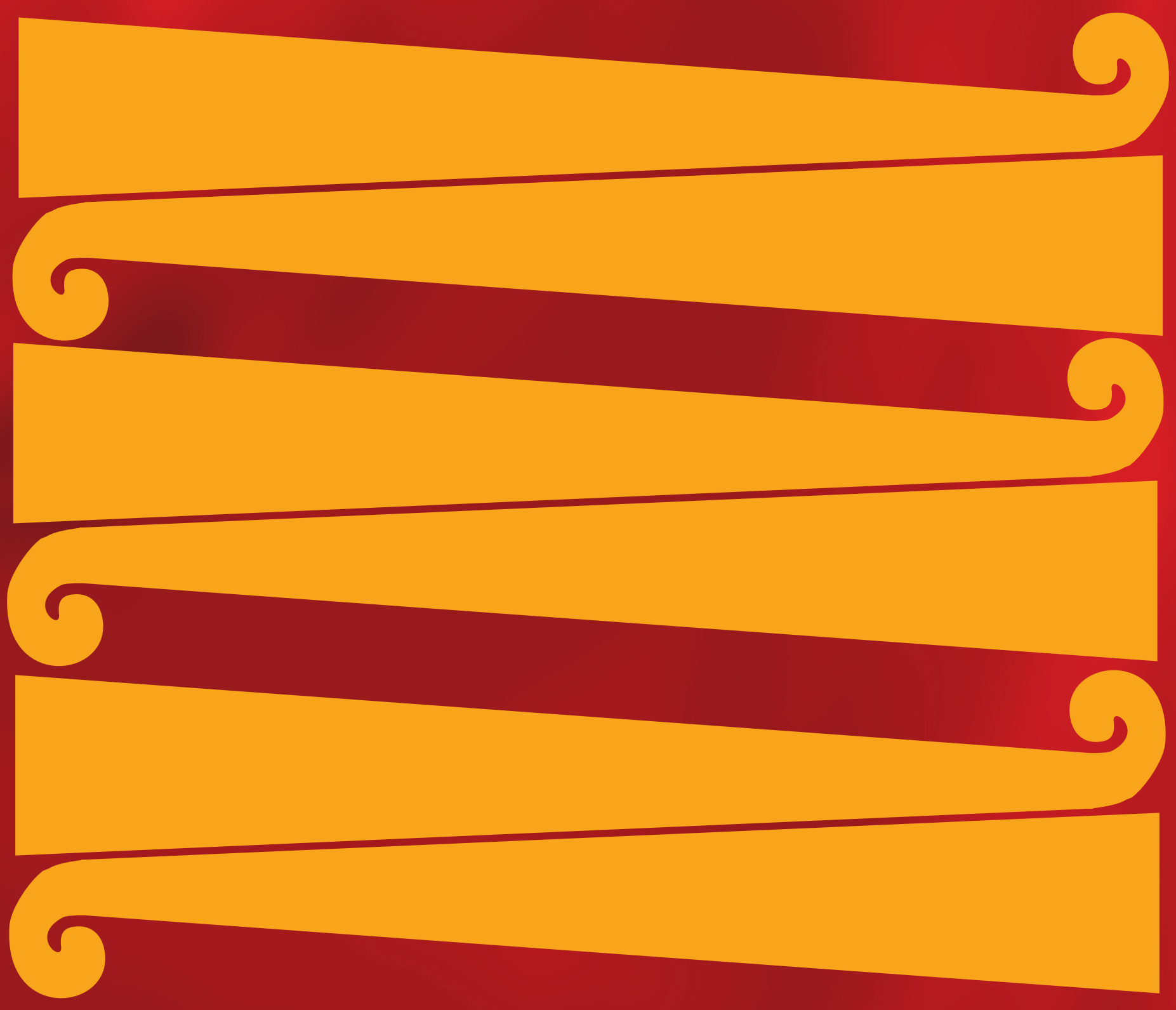


EDITOR:

$$
\text { Greg Lee }
$$

\section{Editorial COMMITTEE:}

Marilyn Blakeney-Williams

Nigel Calder

Ken Carr

Catherine Lang

Greg Lee

Howard Lee

Merilyn Taylor

Hine Waitere

\section{Cover Design and lluustrations}

Donn Ratana

LAYOUT AND DESIGN

Barbara Hudson

\section{EDITORIAL CORRESPONDENCE AND \\ MANUSCRIPTS SUBMITTED FOR PUBLICATION SHOULD BE ADDRESSED TO:}

Research Manager

Wilf Malcolm Institute of Educational

Research

School of Education

The University of Waikato

Private Bag 3105

Hamilton 3240.

email:wmier@waikato.ac.nz

\section{WeBsite:}

http://education.waikato.ac.nz/research/ publication/

BOOKS FOR REVIEW SHOULD BE SENT TO: Research Manager

Wilf Malcolm Institute of Educational

Research

School of Education

The University of Waikato

Private Bag 3105

Hamilton 3240.

email:wmier@waikato.ac.nz

BUSINESS CORRESPONDENCE:

orders, back orders, subscriptions, payments and other enquiries should be sent to:

\section{Teachers and Curriculum}

Hamilton Education Resource Centre PO Box 1387

Hamilton

email: janh@waikato.ac.nz

\section{SUBSCRIPTIONS:}

within New Zealand $\$ 25$ (includes postage) overseas $\$ 40$ (includes postage)

\section{COPYRIGHT:}

School of Education

The University of Waikato

\section{TEACHERS AND}

CURRICULUM

VOLUME 112009

CONTENTS

NOTES For CONTRIBUtORS

EDITORIAL

Gregory Lee

OPINION

Reflections on the Standards David McKenzie

Education for Sustainability (EFS): Citizenship Education for Radical Resistance or Cultural Conformity?

Lynley Tulloch

Education for Now Peter O'Connor

Gifted and Growing Up in a Low-Income Family: Mindsets, Resilience, and Interventions

Nadine Ballam

A Personal Journey: Introducing Reflective Practice into Pre-service Teacher Education to Improve Outcomes for Students Anne Hume

Getting Together to Learn More about ICT Use: Findings from the TELA Evaluation

Ann Harlow and Bronwen Cowie

Will No Child Be Left Behind? The Politics and History of National Standards and Testing in New Zealand Primary Schools Howard Lee and Gregory Lee

\section{Research Note}

Search, Secure, and Interview: Lessons from a Longitudinal Study Peter Stanley

\section{Book ReVIEW}

Nurturing Gifted and Talented Children: A Parent-Teacher Partnership, by Jill Bevan-Brown and Shirley Taylor Reviewed by Nadie Ballam and Peter Stanley 
Teachers ANd Curriculum is an annual publication of the School of Education, The University of Waikato, Hamilton, New Zealand.

It includes articles about curriculum issues, research in the area of curriculum and informed curriculum practice. Reviews of curriculum related books may also be included.

The Opinion item is contributed by a leading New Zealand educationalist.

ISSN 1174-2208

\section{NOTES FOR CONTRIBUtors}

Teachers and Curriculum provides an avenue for the publication of papers that:

- raise important issues to do with the curriculum

- report on research in the area of curriculum

- provide examples of informed curriculum practice

- review books that have a curriculum focus

This peer reviewed journal welcomes papers on any of these from tertiary staff and students, teachers and other educators who have a special interest in curriculum matters. Papers on research may be full papers, or if time or space is at a premium, research notes, that is a 2,000 word summary.

\section{SUBMITTING ARTICLES FOR PUBLICATION}

The editorial committee encourages contributors to ask colleagues to comment on their manuscripts, from an editorial point of view, before submission for publication.

\section{LENGTH}

Manuscripts should not normally exceed 7,000 words, including references and appendices. An abstract must be provided. Abstracts should not be more than 100 words.

\section{Method OF SUBMITTING A PAPER}

Please provide copy in 12 point type in a font compatible with the use of macrons (preferably Helvetica Maori or Times Maori) with line and a half spacing for the main text, and with $20 \mathrm{~mm}$ margins on all edges. Word files are preferred. Please do not include running headers or footers, Follow the style of referencing in the Publication Manual of the American Psychological Association (APA), 5th edition with references in a reference list at the end of the manuscript, rather than footnotes. Manuscripts not submitted in accordance with the above guidelines will be returned to authors for amendment.

\section{Covering LetTer}

When submitting a manuscript to Teachers and Curriculum, authors must, for ethical and copyright reasons, include in a covering letter a statement confirming that (a) the material has not been published elsewhere, and (b) the manuscript is not currently under consideration with any other publisher.

\section{DATE FOR SUbMISSION}

Manuscripts may be submitted at any time.

\section{COPYRIGHT}

Copyright of articles published in Teachers and Curriculum rests with the School of Education, The University of Waikato. Requests to reprint articles, or parts of articles must be made to the Editor via the Hamilton Education Resource Centre. Email: barbh@waikato.ac.nz

\section{ACKNOWLEDGEMENT OF REVIEWERS}

We wish to thank the following people who reviewed for this volume of Teachers and Curriculum. Asterisks indicate those reviewers who contributed more than one review.

\author{
Debbie Hill \\ Gregory Lee * \\ Howard Lee * \\ David McKenzie \\ Trish McMenamin \\ Philip Munro * \\ Anne-Marie O'Neill \\ Roger Openshaw
}




\title{
BOOK REVIEW
}

\author{
NURTURING GIFTED AND TALENTED CHILDREN: \\ A PARENT-TEACHER PARTNERSHIP. \\ Ministry of EdUCATION. (2008). \\ Wellington: Learning Media.
}

\section{NADINe Ballam \\ UNIVERSITY OF WAIKATO AT TAURANGa \\ Peter Stanley \\ UNIVERSITY OF WAIKaTO AT TAURANGA}

The need to cater for students who are gifted and talented is now recognised officially in New Zealand. In 2001, a Ministry of Education working party on gifted education recommended that a book be published that would encourage and assist parents and teachers to form positive and facilitative partnerships in order to "nurture" children who are gifted. This long-awaited book draws on the experiences and reflections of teachers, caregivers, and children, and is intended to serve as a "bridge" between educators and families. In this country, school teachers are able to establish and implement their own programmes for gifted children based on flexible guidelines (Ministry of Education, 2000). This book provides some "common ground" for both schools and communities. Hopefully it will enable both teachers and parents to come to useful understandings about what being gifted and talented can entail, and how these special abilities might best be developed for each young person.

Jill Bevan-Brown and Shirley Taylor, who are the authors of this book, have been careful to include cautions about the identification, characteristics, and milestones of individuals who may be gifted. They emphasise that each child is unique and, while there may be common aspects amongst children who are believed to be gifted, "these children are individuals who may experience many, some, or none of the challenges described" (p. 57). Throughout the text, quick reference icons are used to highlight information to be thought about or followed up. Finally, at the end of the book, to assist caregivers an extensive range of resources is outlined, such as books, websites, and relevant organisations.

The book is made up of two long chapters and the layout, like the walls and backdrop of the contemporary primary classroom, is very "busy". The many images of happy people will invite readers to engage with the content and the variety of these pictures also shows an earnest commitment to diversity, as mandated by the Ministry of Education (2007). There are, however, an array of assumptions within the text which demand examination. Foremost amongst these, perhaps, is the uncertain nature of what it means to be gifted. The book's definition of who is gifted is elusive, and hence expansive, and this means that, inevitably, some children are going to be identified as gifted who are not. Conversely, a child who is gifted according to one school's criteria may not be so when he or she is shifted to a new school.

There is absolutely no reference to expectation research in the text, and yet we have known since Pygmalion in the Classroom (Rosenthal \& Jacobson, 1968), and before, that expectation effects can be very powerful in terms of children's performance. Actually the text has many expectations of its own. For example, children who are gifted can be "quiveringly alive" (p. 54), and these sorts of expectations can be fairly tiring for young people to have to live up to! The authors do well to explain that the emotional "overexcitabilities" referred to here need to be cushioned by support from dedicated adults and peers, if this intensity is to become a "positive and integral part of their giftedness" (p.54). Incidentally, the book expresses a belief that it is possible to be gifted and "well adjusted." This is an understandable hope but it may be that most forms of exceptionality come at a price. In other words, a person simply cannot be "different" and "regular".

It is a fact that the pace and forms of human development in early childhood are such a miracle that it is easy to perceive normal development as exceptional attainment. Masten (2001) invoked the term "ordinary magic" to describe the 
human development processes that produce competence and resilience. It may be that it is much the same in the related sphere of giftedness; there is "regular brilliance" as the parents of any four-year- old dinosaur fanatic knows. In the light of this possibility, what makes the information and suggestions provided in this resource specific to children with special abilities? Should not all students in early childhood centres and schools be exposed to programmes, resources, and opportunities that will extend and nurture them? And should not all parents be encouraged to provide their children with access to programmes, resources, and opportunities, regardless of ability? Significantly, the authors state that "Many learning activities for all children are beneficial for gifted children" (p. 102). Presumably this sentiment also applies in reverse.

This book contributes to the medicalisation of giftedness. It is noteworthy that the authors provide various warnings about this but there are, nevertheless, discussions of the "early signs" of giftedness, comorbidity, bibliotherapy, experiences postdiagnosis, a sense of parental burden and a need for understanding, and an Advice Column for parents. Bevan-Brown and Taylor essentially support the syndrome view (and you're "in" or you are "out"), rather than giving the impression that all traits and abilities are on continuums. This is in keeping with the official trend to medicalise educational and child management issues (e.g., dyslexia has now joined ASD and ADHD). Of course, "gifted and talented" is predisposed towards this fate because it is the one special education condition and label that many parents desire for their sons and daughters. The medicalisation of "these children" (p. 60) is a perilous path to tread, not least, because it builds walls between class mates. The authors observe that "many gifted children are more sensitive than their peers" (p. 46). One might ask legitimately whether the opposite holds true, and whether children without gifts are, comparatively, deficient in feelings.

In Nurturing Gifted and Talented Children some forms of giftedness are given special attention, such as arts, music, academic abilities, and aspects of Maori culture. This is understandable, perhaps, because these talents may be detected more readily in the school context. Nevertheless, these features can also be seen largely as middle-class emphases. The parenting style that is referred to continually in the text is distinctly authoritative (Santrock, 2008). As we know, the associated "demand" and "responsiveness" characteristics of this caregiving approach work much better in Fendalton and Remuera than in Porirua and Otara. There also seems to be a preoccupation with self-esteem, which may be an inherently middle-class pastime, something which probably does not concern top league players, like Sonny Bill Williams or Roy Asotasi, and others who display bodily-kinesthetic special abilities (Gardner, 1993). The recommended provisions of this book are really for small families, because large families generally do not have the time and energy for these concerns.

Economically disadvantaged parents will be less likely to afford to access some of the book's suggestions such as extracurricular activities, clubs, groups, and

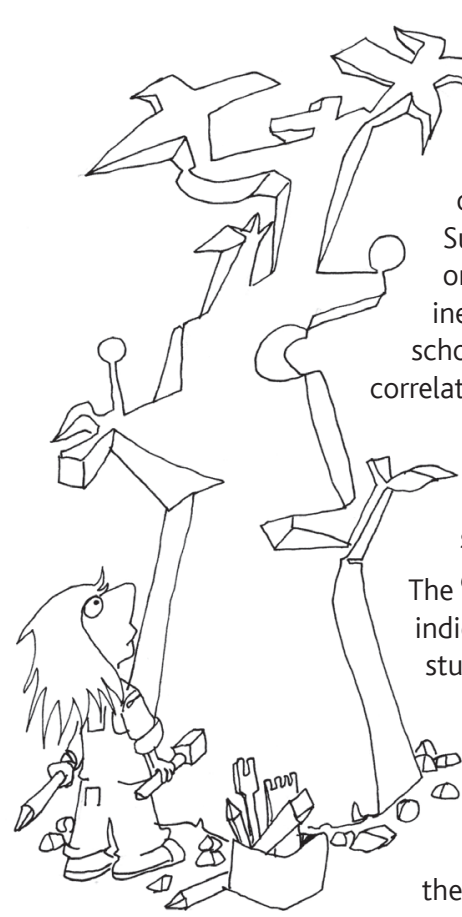

programmes to extend the gifted child. As the first author knows from childhood experience, financially struggling families can tend to avoid involvement in activities that require expense in the form of fees, petrol costs, and equipment or tools. Such families may be able to afford to extend only one child who displays potential. This, inevitably, involves hard choices. As a secondary school teacher, the second author noted a close correlation between youngsters who were in the accelerant classes and their residential street addresses, a correlation that probably reflects the socioeconomic nature of educational success (Biddulph, Biddulph, \& Biddulph, 2003).

The "tail" in our educational statistics, plus other indicators, suggest that significant groups of students remain under-represented in our gifted and talented programmes. According to the Ministry of Education (2000) children from diverse cultures, those with learning difficulties or disabilities, and those from low socioeconomic backgrounds, contain the largest proportion of "hidden gifted." It is also children from these circumstances who are "at risk" of negative life outcomes, who may not have equal access to high quality schools, and who often require particular attention to enable their special abilities to be identified and to flourish. Effectively this book avoids the issue of underrepresentation, and its narrow definition of underachievement is really for the "wellresourced" child who is not doing as well as he or she might.

Nurturing Gifted and Talented Children will be appreciated by many parents for its comprehensiveness. For those from less affluent and educated situations, or with limited understanding of the English language, the information in this book may be simply overwhelming. Also all sorts of "insider" middle-class knowledge is included here. A prominent example is the use of educational jargon. Parents may be alienated by the full child-centred gambit of discovery learning, "risk taking," intrinsic motivation, learning styles, and teachers as facilitators. Furthermore, many of the resources mentioned in the book are described as "useful guides" or as "guidelines only". It may be argued that this imprecise approach might be confusing to some caregivers, depending on their educational and cultural background. Additionally, this book does not address adequately the anxieties and sense of failure that schools can engender in some parents. What we probably need now is a book that truly attempts to cater for those caregivers who cannot cater for themselves.

\section{References}

Biddulph, F., Biddulph, J., \& Biddulph, C (2003). The complexity of community and family influences on children's achievement in New Zealand: Best evidence synthesis. Wellington: Ministry of Education.

Gardner, H. (1993). Multiple intelligences. New York: Basic Books.

Masten, A.S. (2001). Ordinary magic. Resilience processes in development. American Psychologist, 56, 227-238.

Ministry of Education. (2000). Gifted and talented students: Meeting their needs in New Zealand schools. Wellington: Learning Media.

Ministry of Education. (2007). The New Zealand Curriculum. Wellington: Learning Media.

Rosenthal, R., \& Jacobsen, L. (1968). Pygmalion in the classroom. Fort Worth, TX: Harcourt Brace.

Santrock, J.W. (2008). Life-span development (11th ed.). New York: McGraw-Hill. 